\title{
Corticosteroid trials in non-asthmatic chronic airflow obstruction: a comparison of oral prednisolone and inhaled beclomethasone dipropionate
}

\author{
D C Weir, R I Gove, A S Robertson, P Sherwood Burge
}

\begin{abstract}
One hundred and twenty seven adults considered on clinical grounds to have non-asthmatic chronic airflow obstruction entered a randomised, double blind, placebo controlled, crossover trial comparing the physiological response to inhaled beclomethasone dipropionate 500 $\mu \mathrm{g}$ thrice daily with oral prednisolone 40 mg a day, both given for two weeks. One hundred and seven patients completed the study. Response was assessed as change in FEV and FVC measured on the last treatment day, and as change in mean peak expiratory flow (PEF) over the final seven days of treatment from home PEF recordings performed five times daily. A full response to treatment was defined as an increase in FEV or FVC, or an increase in mean daily PEF over the final seven days of treatment, of at least $20 \%$ from baseline values. An improvement in one measurement of at least $15 \%$, or of $10 \%$ in any two measurements, was defined as a partial treatment response. Response to placebo showed a significant order effect, suggesting a carry over effect of active treatment of at least three weeks. Response to active treatment was therefore related to initial baseline values, and compared with placebo by considering responses in the first treatment phase only. A full response to oral prednisolone (16/38) was significantly more common than to placebo $(3 / 35)$. The number of full responses to inhaled beclomethasone (8/ 34) did not differ significantly from the number responding to oral prednisolone or placebo in the first treatment phase, though full and partial responses to inhaled beclomethasone $(12 / 34)$ were significantly more common than those to placebo $(4 / 35)$. When all three treatment phases were considered $44 / 107$ patients showed a full response to one or both forms of corticosteroid treatment, a response to prednisolone (39) occurring more frequently than to inhaled beclomethasone (26). Only 21 of the 44 responders showed a response to both forms of treatment. Inhaled beclomethasone dipropionate $500 \mu \mathrm{g}$ thrice daily was inferior to oral prednisolone $40 \mathrm{mg}$ per day, but better than placebo, in producing improvement in physiological measure-
\end{abstract}

ments in patients thought to have nonasthmatic chronic airflow obstruction. It was, however, an effective alternative in over half of those showing a response to prednisolone.

Oral corticosteroids improve symptoms and lung function in some patients with severe chronic airflow obstruction related to cigarette smoking. ${ }^{1}$ Published trials have in general used doses of oral medication which in the long term would have serious systemic side effects. ${ }^{2-4}$ The efficacy of inhaled corticosteroids in asthma is well established but only two previous studies have looked at the effect of this form of treatment in patients with chronic airflow obstruction, both with small numbers of patients. ${ }^{56}$ The study of Harding and Freedman identified a response to $400 \mu \mathrm{g}$ /day of inhaled betamethasone valerate in only three of six patients who showed a response to oral prednisolone. All responders to the inhaled drug were inpatients and the authors suggest that this may have improved compliance and delivery of the drug to the airways. In the recent study of Wardman et al with 22 outpatients, however, all with good inhaler technique, the five responders to oral prednisolone improved to the same degree after two weeks' treatment with inhaled beclomethasone dipropionate $1500 \mu \mathrm{g}$ per day. The different results may reflect different doses and delivery of the drug to the airways, but the role of inhaled corticosteroids in patients with severe chronic airflow obstruction is still unclear.

The aim of this study was to compare the response to oral prednisolone $40 \mathrm{mg} /$ day with that to inhaled beclomethasone dipropionate $500 \mu \mathrm{g}$ thrice daily in outpatients with nonasthmatic chronic airflow obstruction.

\section{Methods}

SUBJECTS

Outpatients with adult onset chronic airflow obstruction of at least five years' duration and an $\mathrm{FEV}_{1}$ below $70 \%$ predicted were recruited to the trial. Patients were excluded if they had a clinical diagnosis of asthma, respiratory symptoms in childhood, variability in symptoms except in association with infections, acute attacks of wheezing and 
breathlessness, or deterioration after exposure to specific allergens. A lack of a "fixed" element in the airflow obstruction after inhalation of bronchodilator also favoured asthma as the diagnosis. The presence of some reversibility of airflow obstruction in response to inhaled bronchodilators was deliberately not chosen as an exclusion criterion so that its effect on steroid response could be assessed. No patient had received oral or inhaled corticosteroids in the preceding six months. All patients gave informed consent.

\section{MEASUREMENTS}

Spirometric indices were determined on two occasions during the baseline phase before any treatment was given, and on the final day of each treatment period. Patients were asked to refrain from inhaled bronchodilators for six hours before the measurements, and visits were performed at the same time of day. $\mathrm{FEV}_{1}$ and FVC were measured on a dry bellows spirometer (Vitalograph), the mean of three technically satisfactory attempts within $10 \%$ or $100 \mathrm{ml}$ (whichever was the smaller) being used for subsequent analysis. Baseline $\mathrm{FEV}_{1}$ and FVC were taken as the highest mean measurements recorded on the two baseline visits before any treatment.

Lung volumes and single breath carbon monoxide gas transfer ( $T_{L C O}$ ) were determined once during the baseline period and at the end of each treatment phase. A closed circuit helium dilution technique was used to measure lung volume subdivisions, rebreathing being continued until the concentration of helium was stable or for a maximum of 20 minutes. Single breath TLCO was taken as the mean of two satisfactory manoeuvres within $15 \%$ of each other.

Airflow reversibility in response to salbutamol and ipratropium bromide was determined during the baseline period. Two doses of salbutamol $(200 \mu \mathrm{g}$ and $10 \mathrm{mg})$ were administered sequentially, and the response was determined 20 minutes after each dose. On a subsequent day 72 and $500 \mu \mathrm{g}$ of ipratropium bromide were given and the spirometric response was assessed 25 minutes after each dose. The smaller dose of each drug was given by a metered dose inhaler and the larger dose by an Inspiron mini-Neb nebuliser, the drug being nebulised to dryness. Bronchial responsiveness to inhaled histamine was determined by the method of Cockroft et $a l^{7}$ on the second baseline visit if the FEV was above 0.61 .

After the second baseline visit patients were asked to measure peak expiratory flow rate (with a mini Wright's peak flow meter) four hourly during waking hours at home, and record the best of at least three attempts with the best two within $20 \mathrm{l} / \mathrm{min}$. All baseline values were obtained during the two weeks before the first treatment phase and mean daily PEF was calculated over the final seven days of this period. Diurnal variation in PEF was calculated from the same readings as mean daily maximum PEF (mean daily maximum PEF minus mean daily minimum PEF divided by mean daily PEF).
Serum IgE concentrations were measured by a PRIST technique and skinprick tests performed with house dust, Dermatophagoides pteronyssinus, Aspergillus fumigatus, cat fur, and a control solution, a positive result being defined as a weal $2 \mathrm{~mm}$ greater than that obtained with the control solution in two or more tests.

Inhaler technique was checked at each visit and corrected as necessary. All patients continued their usual bronchodilator treatment unchanged during the trial, and were instructed to maintain a constant timing between doses and $P E F$ readings.

\section{DESIGN}

The trial was a randomised, double blind, double dummy, crossover study designed to compare inhaled beclomethasone dipropionate $500 \mu \mathrm{g}$ thrice daily, oral prednisolone 40 $\mathrm{mg} /$ day, and placebo. Each treatment was given for two weeks followed by a two week washout period before the next treatment period. The first treatment period was preceded by a four week baseline period. Patients attended the laboratory on days 1 and 14 of the baseline period for initial investigations, and on the last day of each treatment period for subsequent assessments.

\section{ANALYSIS}

A full response to treatment was defined as an improvement in absolute values of $\mathrm{FEV}_{1}$ or FVC on the final treatment day, or mean PEF over the last seven days of treatment, of at least $20 \%$ when compared with baseline. An improvement of at least $15 \%$ in any one measure or at least $10^{\circ}$ in any two measures was defined as a partial treatment response.

Baseline data were compared by means of a paired or unpaired Student's $t$ test for normally distributed data or a Wilcoxon signed rank or rank sum test for data not normally distributed. Treatment order effect was assessed by a logit regression on proportions, the GLIM statistical package being used. ${ }^{8}$ Active treatment response rates were compared by McNemar's test, and the responses to the treatments given during the first phase by a $\chi^{2}$ test.

All predicted values are derived from published equations. ${ }^{9}$

\section{Results}

Of the 127 patients who entered the study, 107 completed the protocol. Eleven patients defaulted at subsequent visits: six had an infective exacerbation of their disease, one died of an unrelated cause during the run in period, and two had complications during the oral prednisolone phase (exacerbation of chronic duodenal ulceration in one, left ventricular failure in the other). The mean age (63 years) and the $\mathrm{FEV}_{1}$ and $\mathrm{FVC}(39 \%$ and $70 \%$ predicted) of those withdrawn were similar to the mean values in patients who completed the study. The baseline lung function characteristics of the study group are given in table 1 and details of smoking and atopy in table 2 .

There was a significant order effect in the 
Table 1 Baseline lung function characteristics of the study group (mean $(S D)$ values unless otherwise indicated)

\begin{tabular}{|c|c|}
\hline $\begin{array}{l}\text { (25F) Number } \\
\text { Age: years } \\
\text { FEV }{ }_{1} \text { l litres } \\
{ }_{0} \text { predicted } \\
\text { Forced vital capacity: o }{ }^{\circ} \text { predicted } \\
\text { Peak flow (PEF): }{ }^{\circ} \text { o predicted } \\
\text { Total lung capacity: }{ }^{\circ} \text { o predicted } \\
\text { Residual volume: }{ }^{\circ} \text { predicted } \\
\text { Transfer coefficient: }{ }^{\circ} \text { predicted } \\
\text { Diurnal variation in PEF: }{ }^{\circ} \text { mean } \\
\text { PC }_{20}(\mathrm{mg} / \mathrm{ml}): \text { geometric mean (range) }\end{array}$ & $\begin{array}{l}107(25 \mathrm{~F}) \\
62 \cdot 9(9 \cdot 0) \\
1 \cdot 19(0 \cdot 47) \\
44 \cdot 2(16 \cdot 7) \\
79 \cdot 2(19 \cdot 0) \\
52 \cdot 4(17 \cdot 9) \\
121 \cdot 5(19 \cdot 4) \\
173 \cdot 6(52 \cdot 0) \\
77 \cdot 8(31 \cdot 7) \\
19 \cdot 8(9 \cdot 9) \\
0 \cdot 81(0 \cdot 03-16 \cdot 0)\end{array}$ \\
\hline $\begin{array}{l}F E V_{1} \text { : indices of reversibility of airflow } \\
\text { As }{ }^{\circ} \text { initial FE } V_{1} \text {, in response to: } \\
10 \mathrm{mg} \text { salbutamol } \\
200 \mu \mathrm{g} \text { salbutamol } \\
500 \mu \mathrm{g} \text { ipratropium bromide } \\
72 \mu \mathrm{g} \text { ipratropium bromide }\end{array}$ & $\begin{array}{l}18 \cdot 0(15 \cdot 9) \\
11 \cdot 4(11 \cdot 2) \\
20 \cdot 1(17 \cdot 0) \\
13 \cdot 1(11 \cdot 7)\end{array}$ \\
\hline $\begin{array}{l}\text { As }{ }^{\circ}{ }^{\circ} \text { (predicted minus initial) } \mathrm{FEV}_{1} \text {, in } \\
20 \mathrm{mg} \text { salbutamol } \\
200 \mu \mathrm{g} \text { salbutamol } \\
500 \mu \mathrm{g} \text { ipratropium bromide } \\
72 \mu \mathrm{g} \text { ipratropium bromide }\end{array}$ & $\begin{array}{l}\text { onse to: } \\
15 \cdot 5(16 \cdot 8) \\
10 \cdot 9(13 \cdot 7) \\
19 \cdot 2(26 \cdot 1) \\
12 \cdot 5(16 \cdot 4)\end{array}$ \\
\hline
\end{tabular}

$\mathrm{PC}_{20}$-provocative concentration of histamine causing a $20^{\circ}$ 。 fall in $\mathrm{FEV}_{1}$.

Table 2 Smoking and atopy in the 107 subjects

\begin{tabular}{ll}
\hline Number of: & \\
Current smokers & 41 \\
Ex-smokers & 54 \\
Lifelong non-smokers & 12 \\
Mean (SD) cigarette consumption & $761(547)$ \\
$\quad$ (cigarette years) & 77 \\
Number with chronic bronchitis & $74(3-4500)$ \\
Serum IgE (kU/1): geometric mean (range) & 46 \\
Number with positive skin test responses & 4 \\
\hline
\end{tabular}

*Medical Research Council definition.

response to placebo, in that the placebo response rate was greater when placebo had been preceded by active treatment $\left(\chi_{1}^{2}=5.06\right.$, $\mathrm{p}<0.05$ : table 3 ); this was not seen with the response to prednisolone or to beclomethasone dipropionate $\left(\chi_{1}^{2}=0.75\right.$ and $\left.\chi_{1}^{2}=0.02\right)$. Because of this order effect, response to treatment was defined with respect to initial baseline values before any trial treatment had been given, and the two active treatments were compared with placebo by a parallel group analysis of the first treatment phase data.

ANALYSIS OF DATA AS A PARALLEL GROUP STUDY USING THE FIRST TREATMENT PHASE ONLY

On entry into the study patients randomised to receive placebo, beclomethasone, or prednisolone for the initial treatment phase, did not differ in terms of baseline physiological characteristics (table 4 ). The number of patients showing a full response to prednisolone $(16 / 38)$

Table 4 Baseline characteristics of the groups according to the treatment received in the first phase (mean (SD) unless otherwise indicated)

\begin{tabular}{|c|c|c|c|}
\hline & Placebo & Beclomethasone & Prednisolone \\
\hline $\begin{array}{l}\text { Number } \\
\text { Age: years } \\
\text { FEV }_{1}: \text { litres } \\
\quad \% \text { predicted }\end{array}$ & $\begin{array}{l}35(7 F) \\
64 \cdot 2(8 \cdot 1) \\
1 \cdot 15(0 \cdot 48) \\
42 \cdot 8(14 \cdot 2)\end{array}$ & $\begin{array}{l}34(11 \mathrm{~F}) \\
60 \cdot 8(10 \cdot 1) \\
1 \cdot 21(0 \cdot 53) \\
45 \cdot 1(18 \cdot 2)\end{array}$ & $\begin{array}{l}38(7 \mathbf{F}) \\
63 \cdot 7(8 \cdot 5) \\
1 \cdot 20(0 \cdot 43) \\
44 \cdot 7(17 \cdot 7)\end{array}$ \\
\hline \multicolumn{4}{|l|}{$\begin{array}{l}\text { Reversibility of airflow obstruction } \\
\text { (as \% baseline) in response to: }\end{array}$} \\
\hline $\begin{array}{l}10 \mathrm{mg} \text { salbutamol } \\
500 \mu \mathrm{g} \text { ipratropium bromide } \\
\text { Cigarette consumption: }\end{array}$ & $\begin{array}{l}16 \cdot 3(18 \cdot 3) \\
20 \cdot 0(18 \cdot 5)\end{array}$ & $\begin{array}{l}20 \cdot 2(16 \cdot 3) \\
22 \cdot 6(19 \cdot 5)\end{array}$ & $\begin{array}{l}17 \cdot 7(13 \cdot 3) \\
18 \cdot 0(12 \cdot 9)\end{array}$ \\
\hline $\begin{array}{l}\text { Cigarette years } \\
\text { Number of: }\end{array}$ & $712(522)$ & $620(486)$ & $896(566)$ \\
\hline \multicolumn{4}{|l|}{ Number of: } \\
\hline $\begin{array}{l}\text { Ex-smokers } \\
\text { Ex-smokers }\end{array}$ & $\begin{array}{l}11 \\
19\end{array}$ & $\begin{array}{l}10 \\
20\end{array}$ & 28 \\
\hline Lifelong non-smokers & 5 & 4 & 3 \\
\hline
\end{tabular}

There are no significant differences between groups.
Table 3 Number of full responders (partial responders in parentheses) to each treatment according to the phase in which it was administered

\begin{tabular}{lrrr}
\hline & Phase 1 & \multicolumn{1}{c}{ Phase 2 } & \multicolumn{1}{c}{ Phase 3 } \\
\hline Placebo & $3(1) / 35$ & $7(1) / 31$ & $12(0) / 41^{\star \star}$ \\
Beclomethasone & $8(4) / 34$ & $10(4) / 41$ & $8(2) / 32$ \\
Prednisolone & $16(1) / 38$ & $12(1) / 35$ & $11(3) / 34$ \\
\hline
\end{tabular}

$\star \star p<0.05$ for treatment order effect.

was significantly greater than the number showing a similar response to placebo (3/35, $\left.\chi_{1}^{2}=10.64 ; \mathrm{p}<0.005\right)$. A full response occurred more frequently with beclomethasone $(8 / 34)$ than with placebo, though this was not significant $\left(\chi_{1}^{2}=2 \cdot 22 ; \mathrm{NS}\right)$. When partial responses are included in the analysis the response rate for both inhaled beclomethasone (12/34) and oral prednisolone (17/ 38) was significantly greater than that for placebo $\left(4 / 35: \quad \chi_{1}^{2}=5.51, \quad p<0.02 ; \quad\right.$ and $\chi_{1}^{2}=9.86, \mathrm{p}<0.002$ respectively). There was no significant difference in the response to either active drug in this analysis either for full responders $\left(\chi_{1}^{2}=2 \cdot 79, \mathrm{p}<0 \cdot 1\right)$ or when full and partial responders were considered $\left(\chi_{1}^{2}=0.67\right)$.

ANALYSIS OF DATA FROM ALL THREE TREATMENT PHASES IN THE CROSSOVER STUDY

When all three treatment phases were considered to allow within subject comparison of response, 21 patients showed a full response to both prednisolone and beclomethasone. A further 18 patients responded to prednisolone only and five to beclomethasone only. Six of the 18 prednisolone only responders showed a partial response to beclomethasone and one of the five beclomethasone only responders showed a partial response to oral prednisolone. In total, $44 / 107(41 \%)$ patients showed a full response to prednisolone or beclomethasone and a further six a partial response. The response rate was significantly greater with prednisolone than beclomethasone (Mcnemar's test $2 \cdot 71, \mathrm{p}<0.05$ ).

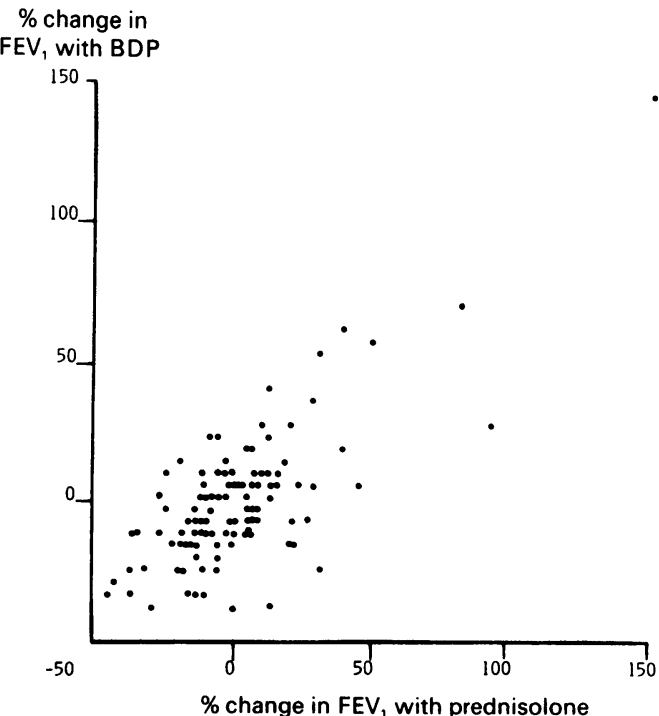

Figure 1 Percentage change in FEV, from baseline values in individual patients after treatment with prednisolone and beclomethasone (BDP). Slope of least squares regression line $=0.72(S E 0.06)$. 
Figure 2 Percentage change in mean daily peak expiratory flow $(P E F)$ from baseline value in individual patients after prednisolone and Slope of least squares regression line $=0.46$ (SE 0.05). treatment with beclomethasone (BDP).

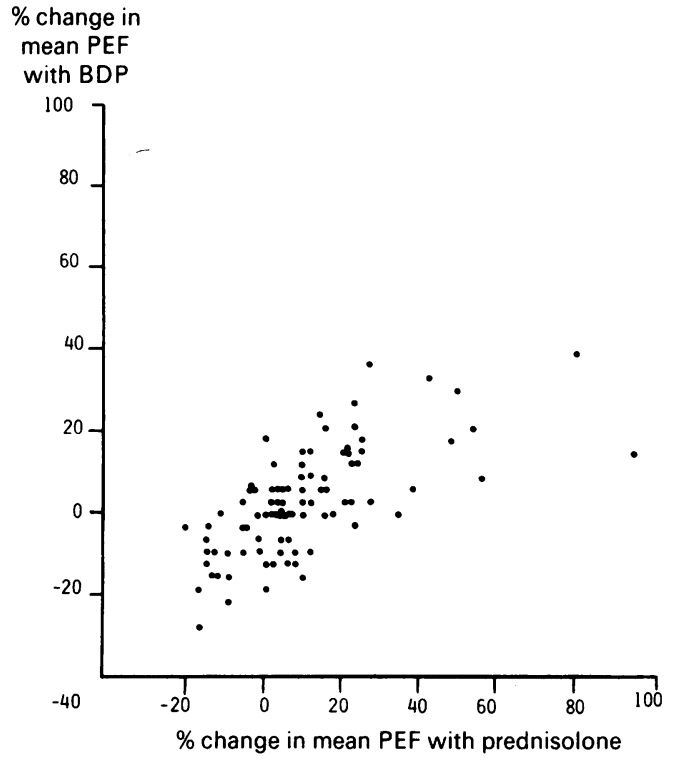

Figure 3 Percentage change in forced vital capacity (FVC) from baseline value in individual patients after treatment with prednisolone and beclomethasone ( $B D P$ ). Slope of least squares regression line $=0.62$ (SE 0.07).

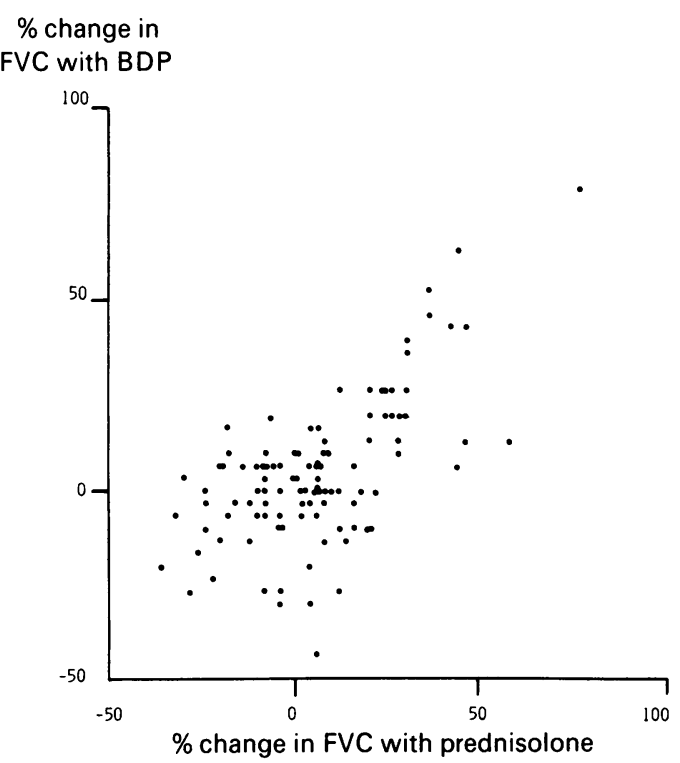

The responses of individual patients to oral prednisolone and inhaled beclomethasone are shown in figures 1-3 for $\mathrm{FEV}_{1}, \mathrm{FVC}$, and PEF. The slope of the least squares regression line for each plot is significantly different from the line of identity, indicating a greater effect of prednisolone on each measurement.

A full response to an active treatment occurred on 65 occasions. The measurements in which a response was seen on these occasions are shown in the Venn diagram (fig 4). A full response was seen in all three measurements on only seven occasions and in two of the measurements on a further 17 occasions; in most cases (41) a full response was seen in only one measurement.

In the 44 patients who had a full response to prednisolone or beclomethasone the change in the measurement showing the greatest response was expressed as a percentage of the patient's predicted value, a measure independent of baseline $\mathrm{FEV}_{1}$ (fig 5). The responders remained distinct from the nonresponders.

The mean reversibility in $\mathrm{FEV}_{1}$ in response to $10 \mathrm{mg}$ inhaled salbutamol was $18 \%$, expressed as a percentage of the prebronchodilator value (table 1). If expressed in terms of potential reversibility - that is, as a percentage of the predicted minus the prebronchodilator value-the mean improvement was $15.5 \%$. Only 13 patients showed an increase in this measurement of over $50 \%$, indicating that most of the patients had relatively fixed airflow obstruction. Response to prednisolone or beclomethasone or both in the 13 "reversible" patients $(4 / 13)$ was similar to that seen in the "irreversible" patients $\left(40 / 94 ; \chi_{1}^{2}=0.64 \mathrm{NS}\right)$.

Cigarette consumption in the patients varied from zero to 2520 cigarette years, with a mean of 761 cigarette years (table 2 ). Twelve patients claimed to be life long non-smokers. Eighty one patients admitted to a cigarette consumption in excess of 400 cigarette years. Full and partial responses to prednisolone or beclomethasone or both were similar in this group of heavier smokers (39/81) and in the remaining patients $\left(11 / 26 ; \chi_{1}^{2}=0.57 ; \mathrm{NS}\right)$.

\section{Discussion}

The finding of a significant order effect with placebo treatment complicated the analysis of the data from this trial. The analysis of the data on the first treatment phase removes the confounding influence of the order effect and shows that both active treatments are superior to placebo in producing a physiological response in these patients. In this analysis oral prednisolone produced a response in more subjects than inhaled beclomethasone, though the difference was not significant. Previous studies have not always commented on an order effect, though some have used a single blind design that would avoid this problem. ${ }^{36}$ Two smaller studies with a crossover design found no treatment order effect, ${ }^{10}{ }^{11}$ possibly because of the smaller numbers of patients.

Although in our study the order effect was seen only with placebo it might have occurred to some extent with active treatment. The lack 


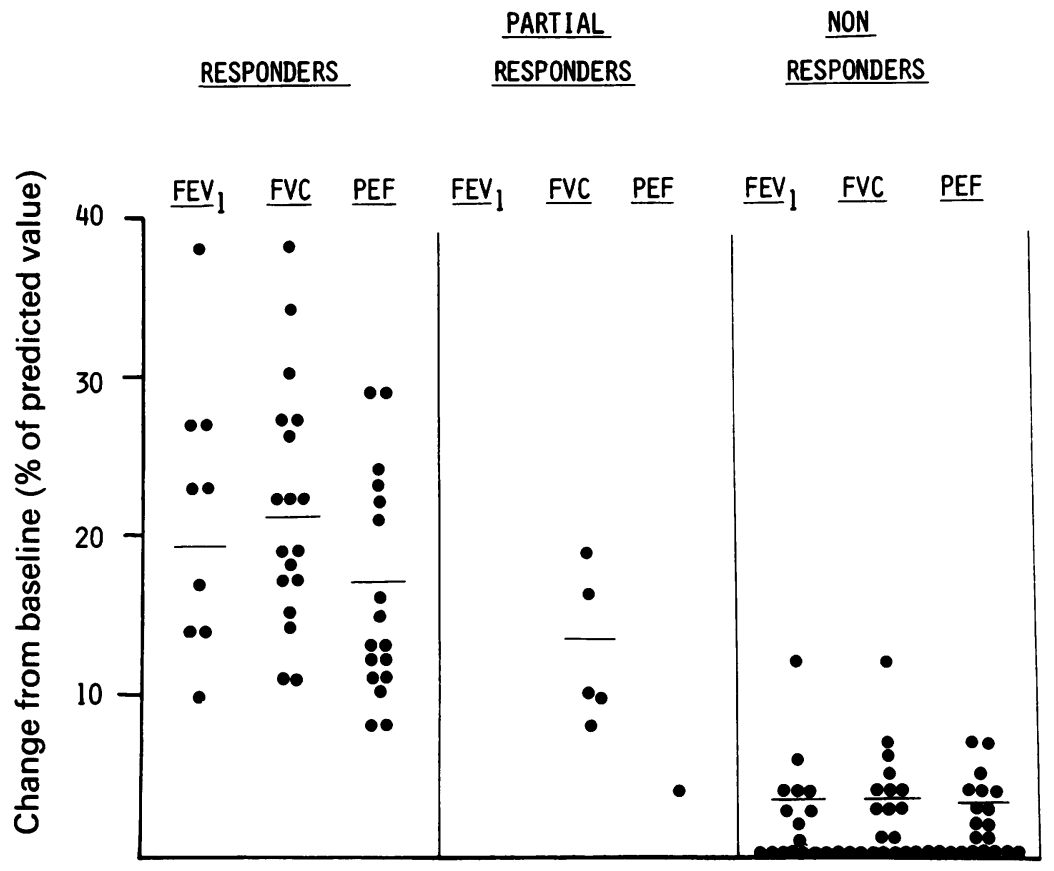

Figure 5 Change from baseline after treatment in the measurement that showed the greatest percentage change. The change is expressed as a percentage of the predicted value for the patient for that measurement. The horizontal lines represent the mean response of all the patients who showed a positive change.

of any detectable order effect for the response to prednisolone and beclomethasone suggests that the action of the second active treatment is more powerful than the carry over effect of the initial treatment. We feel justified therefore in using data from all three treatment phases to further compare individual responses to prednisolone and beclomethasone. When this was done prednisolone was superior to beclomethasone in producing a response, though over half of the patients showing a response to prednisolone also responded to inhaled beclomethasone. The reason why five patients responded to inhaled beclomethasone only is not clear.

Our study may be criticised for the response criteria adopted. Response was expressed in terms of percentage change from the baseline value, a criterion used in previous trials. ${ }^{6} 101113$ The validity of such a definition is questionable when the absolute value of the variable studied is low. In these circumstances small changes that are within the error of measurement of the variable may assume undue significance. Only $4 \%$ of our responders, however, showed a change in $\mathrm{FEV}_{1}$ or FVC that was within the $95 \%$ confidence limits for short term variability in $\mathrm{FEV}_{1}$ and FVC published recently. ${ }^{14}$ Previous studies of longer term variability in spirometric indices in similar patients suggest that our criteria are reasonable. ${ }^{15}{ }^{16}$ Expressing change as a percentage of a measure independent of the baseline-that is, the predicted value-did not suggest that any responders had been misclassified (fig 5). One partial responder and two non-responders may have been wrongly classified.

Symptomatic change was not determined formally in all patients. Visual analogue scales for five symptoms and six minute walking distances were, however, determined in the first 83 patients recruited to the trial. ${ }^{17} \mathrm{Six}$ minute walking distances improved significantly with both active treatments in the steroid responsive patients, whereas no effect was seen with treatment in the non-responders. Visual analogue scores showed a wide variation and, although they improved in all response groups with treatment, the changes were not significant.

A further possible criticism of our results is that because of the "soft" entry criteria we inadvertently included patients with missed asthma in the study population. The criteria were chosen to reflect clinical practice and only where the physician was unsure of the benefit of steroid treatment - that is, where asthma was not present-was a patient entered. Those who had had respiratory disease in childhood were excluded, which eliminated many patients with asthma. Not all patients were current smokers or ex-smokers, although most had smoked heavily. Many patients showed a degree of reversibility in response to inhaled bronchodilators that was within the "asthmatic" range of $20^{\circ}{ }_{0}$ or more of the prebronchodilator $\mathrm{FEV}_{1}$. This, however, is a misleading measure of reversibility in patients with a low prebronchodilator $\mathrm{FEV}_{1}$. A better indication of reversibility is obtained by considering the reversibility as a percentage of the predicted $\mathrm{FEV}_{1}$ minus the prebronchodilator value (table 1). Most of our patients had largely irreversible airflow obstruction. Response to one or both corticosteroid treatments was not related to past cigarette consumption or to reversibility in response to inhaled salbutamol, suggesting that our patients were predominantly nonasthmatic. The degree of response to corticosteroids shown in figure 5 shows a unimodal distribution, again suggesting that the patients came from a single disease group. Hence we believe that most of the patients were not asthmatic, and that our findings are relevant to patients diagnosed as having chronic airflow obstruction in clinical practice.

The trial of Wardman et $a l^{6}$ showed that $1500 \mu \mathrm{g}$ beclomethasone/day was comparable to oral prednisolone $30 \mathrm{mg}$ in patients similar to ours, in terms both of the number showing a response and of the degree of improvement seen in the measure of lung function. Like Harding and Freedman, ${ }^{5}$ we have not found this to be the case. The likeliest explanation for this is differences in selection of patients and perhaps in deposition of aerosol in the lung. We attempted to optimise inhaler technique in our group by checking and correcting technique at each visit, but possibly improved delivery of the drug to the airways by means of a spacing device would have produced more responders to beclomethasone. Our results would suggest, however, that inhaled beclomethasone $500 \mu \mathrm{g}$ thrice daily should be considered an effective treatment in over half of patients with nonasthmatic airflow obstruction who show a response to oral prednisolone $40 \mathrm{mg}$ daily.

The contribution of the following is gratefully acknowledged: Dr D Geddes for help with the trial design, Allen and Hanburys Ltd for financial support and providing the inhalers, 
Dr R Holder (University of Birmingham) for statistical advice, and Ms J Shepherd and Dr R Cayton and the staff of the respiratory function laboratory, East Birmingham Hospital, for practical assistance.

1 Rudd RM. Corticosteroids in chronic bronchitis. $\mathrm{Br}$ Med 1984;288:1553-4.

2 Stokes TC, Shaylor JM, O'Reilly JF, Harrison BDW. Assessment of steroid responsiveness in patients with chronic airflow obstruction. Lancet 1982;ii:345-8.

3 Mandella LA, Manfreda J, Warren CPW, Anthonisen NR. Steroid response in stable chronic obstructive pulmonary disease. Ann Intern Med 1982;96:17-21.

4 Franklin W, Michelson AL, Lowell FC, Schiller IW. Bronchodilators and corticosteroids in the treatment of obstructive pulmonary emphysema. $N$ Engl J Med 1958;258:774-8.

5 Harding SM, Freedman S. A comparison of oral and inhaled steroids in patients with chronic airways obstruction: steroids in patients with chronic airways obstruction:

6 Wardman AG, Simpson FG, Knox AJ, Page RL, Cooke NJ The use of high dose inhaled beclomethasone dipropionate as a means of assessing steroid responsiveness in obstructive airways disease. $\mathrm{Br} J$ Dis Chest 1988;82 168-71.

7 Cockroft DW, Killian DN, Mellon JJA, Hargreave FE Bronchial reactivity to inhaled histamine: a method and clinical survey. Clin Allergy 1977;7:235-43.

8 Baker RJ, Nelder JA. The GLIM system. Release 3. Oxford: Numerical Algorithms Group, 1978.

9 Quanjer P, ed. Standardised lung function testing. Bull Eur Physiopathol Respir 1983;19(suppl 5):1-95.

10 Mitchell DM, Gildeh P, Dimond AH, Collins JV. Value of serial peak expiratory flow measurements in assessing treatment response in chronic airflow limitation. Thorax 1986;41:606-10.

11 Mitchell DM, Gildeh P, Rehahn M, Dimond AH, Collins JV. Effects of prednisolone in chronic airflow limitation. JV. Effects of prednis

12 Weir DC, Robertson AS, Gove RI, Burge PS. Time course of response to oral and inhaled corticosteroids in nonasthmatic chronic airflow obstruction. Thorax 1990;45:117-20

13 Lam WK, So SY, Yu DYC. Response to oral corticosteroids in chronic airflow obstruction. $\mathrm{Br} J$ Dis Chest 1983;77:189-98.

14 Tweeddale PM, Alexander F, McHardy GJR. Short term variability in $\mathrm{FEV}_{1}$ and bronchodilator responsiveness in patients with obstructive ventilatory defects. Thorax 1987;42:487-90.

15 Mungall IPF, Hainsworth R. Assessment of respiratory function in patients with chronic obstructive airways function in patients with chron

16 Rozas CJ, Goldman AL. Daily spirometric variability: normal subjects and subjects with chronic bronchitis with and without airflow obstruction. Ann Intern Med 1982;142:1287-91.

17 Gove RI. Predictors and features of a response to corticosteroids in chronic airflow obstruction. MD thesis, University of London, 1986:41. 